\title{
Calcaneal nonunion: three cases and a review of the literature
}

\author{
Tim Schepers $\cdot$ Peter Patka
}

Received: 25 May 2007 / Published online: 15 December 2007

(C) The Author(s) 2007

\begin{abstract}
The long-term follow-up of intra-articular calcaneal fractures is often accompanied by complications. Frequently occurring are arthrosis, arthrofibrosis of the subtalar joint, and malunion. Uncommon is the calcaneal nonunion. A total of three cases is presented in this report, including a review of the literature. The occurrence of a nonunion appears to be more common after conservative treatment, but the pathophysiology remains unclear, however smoking may play a role.
\end{abstract}

Keywords Calcaneus $\cdot$ Fracture $\cdot$ Pseudarthrosis · Nonunion

\section{Introduction}

During long-term follow-up after intra-articular calcaneal fractures complications frequently occur. In clinical practice, arthrosis and arthrofibrosis of the subtalar joint, malunion and nonunion are encountered [8, 12]. Nonunion is only rarely found, and studies concerning complications after intra-articular calcaneal fractures do not describe this complication [5, 7]. In only five studies, including nine patients, reports on nonunion are made $[3,6$, 10, 11, 13]. Three patients with a pseudarthrosis after an intra-articular fracture of the calcaneus are presented in the current study.

T. Schepers $(\bowtie) \cdot$ P. Patka

Department of Surgery-Traumatology, Erasmus MC, University Medical Center Rotterdam, Room H 974, Rotterdam 3000 CA, The Netherlands

e-mail: t.schepers@erasmusmc.nl

\section{Cases}

Case 1

A male adult (age 49) fell from a height of $2 \mathrm{~m}$ fracturing his left calcaneus. According to the Essex-Lopresti classification he sustained a joint-depression type, and a type IIA fracture according to the Sanders classification. There was no injury to the soft tissues. After 6 days the fracture was operated on, using percutaneous reduction and fixation according to the technique of Forgon and Zadravecz [9]. Post-operative treatment consisted of active range of motion exercises and 3 months non-weight bearing. Initial recovery was uncomplicated. Two years after the trauma, the patient however returned to our outpatient department with complaints of painful walking, and unable to work. A computed tomography (CT) scan showed a pseudarthrosis of the calcaneus and talocalcaneal joint surface incongruence (Fig. 1). An injection of $10 \mathrm{cc}$ lidocain in the subtalar joint temporarily reduced pain. A subtalar joint arthrodesis was performed, fusing the talus and calcaneus with the use of bone graft gained from the iliac crest. After 1 year the arthrodesis has fully consolidated, the patient is pain free, but has currently not yet returned to work.

\section{Case 2}

A female patient, aged 53, sustained a fracture of the right calcaneus after a fall from the stairs (Essex-Lopresti joint depression type, Sanders type IIB). As patient was seen three weeks after the trauma, the initial treatment was conservatively, consisting of 1 week of plaster-of-Paris and 3 months non-weight bearing with active range of motion exercises. Two months later the patient was unable to bear weight at the fractured side due to pain. A CT showed a 

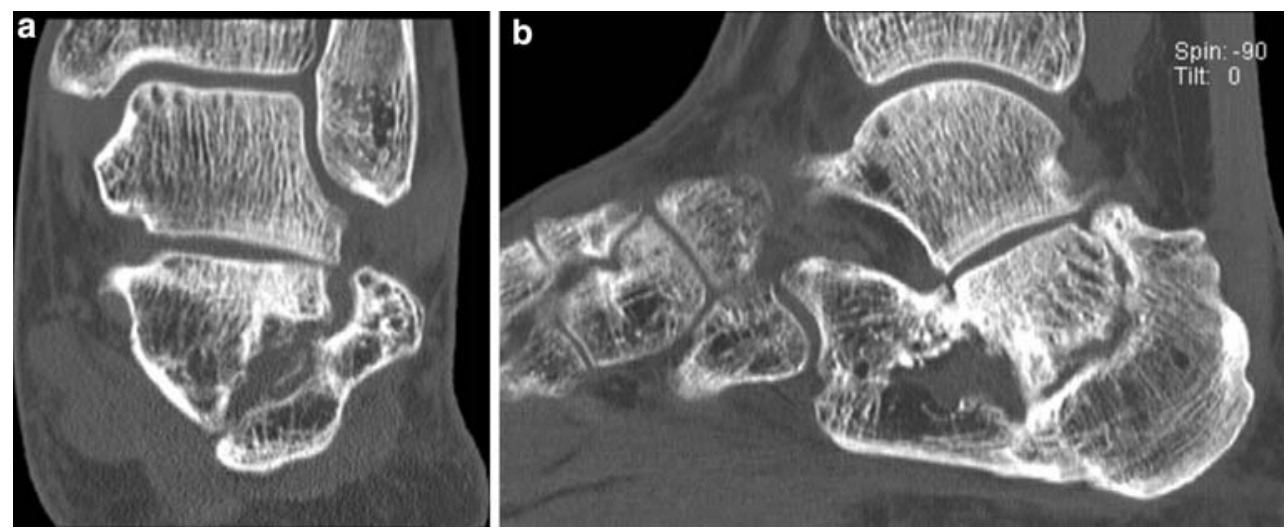

Fig. 1 a Case 1: Axial CT-scan image 22 months after percutaneous reduction and fixation showing nonunion; b Sagittal view
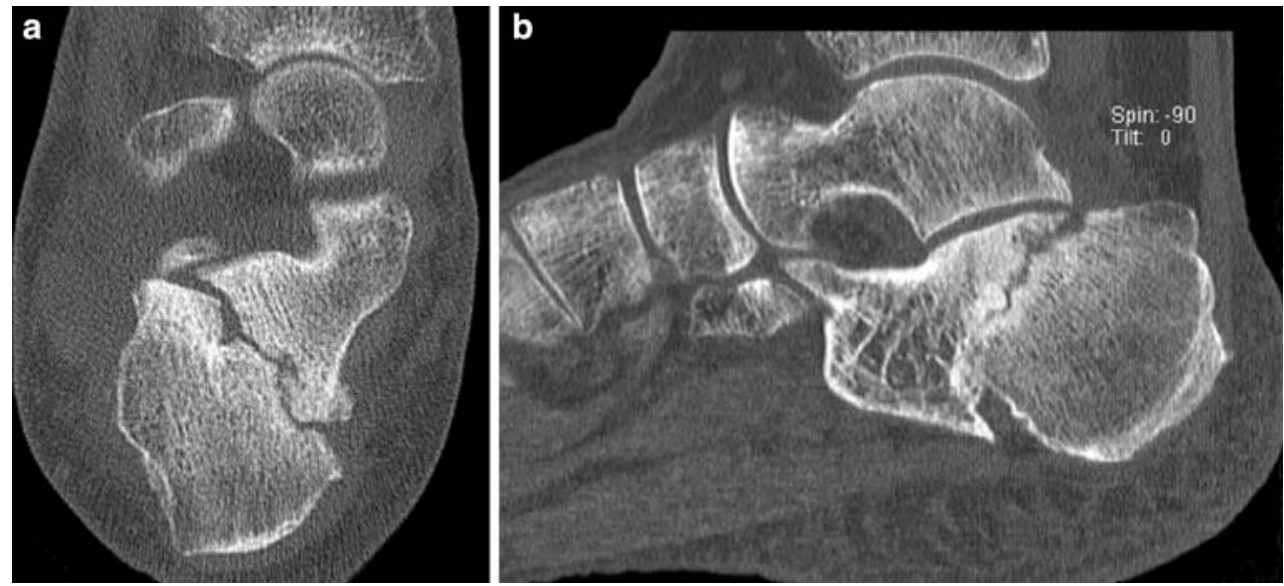

Fig. 2 a Case 2: Semi-coronal CT-scan image 5 months after conservative treatment showing delayed union; b Sagittal view

delayed union of the calcaneus (Fig. 2). Peroperatively, 6 months after trauma, there was a nonunion of the fracture, without apparent signs of arthrosis of the talocalcaneal joint surface. Because of the smoking habits and diabetes in this patient, as independent causes of high wound complication rates, an early subtalar arthrodesis with bone graft harvested from the tibial tuberosity was performed instead of a correcting osteotomy. Three months after the salvage operation the arthrodesis had consolidated, the patient is walking pain free.

\section{Case 3}

A male adult, of 39-years-old, sustained a bilateral calcaneal fracture after jumping of a first storey balcony. The radiographs showed a comminuted intra-articular calcaneal fracture according to the Essex-Lopresti classification at both sides and Sanders type IIC and IIIAC fractures on the left and right foot, respectively. Initial treatment was conservative, consisting of 1 week of plaster-of-Paris and 3 months non-weight bearing with active range of motion exercises. Thirteen months later the patient returned to the outpatient department with complaints of pain at the left heel. Additional radiographs and CT showed a nonunion of the fracture of the left calcaneus (Fig. 3). A subtalar arthrodesis was performed, with bone graft from the tibial tuberosity. Two cannulated screws were inserted from the tuberosity of the calcaneus, bridging the primary fracture line. The after treatment was complicated with a superficial infection, which could be treated adequately with intravenous antibiotics. Six months after the secondary fusion the patient was able to walk pain free.

\section{Discussion}

Improper healing after an intra-articular calcaneal fracture carries a high morbidity. Three groups: A, malunion; B, nonunion; and $\mathrm{C}$, osteonecrosis, were suggested by Zwipp [13]. These groups are further divided according to the presence of joint incongruence, varus/valgus, loss of height, translation of bones and luxation. Treatment of these 

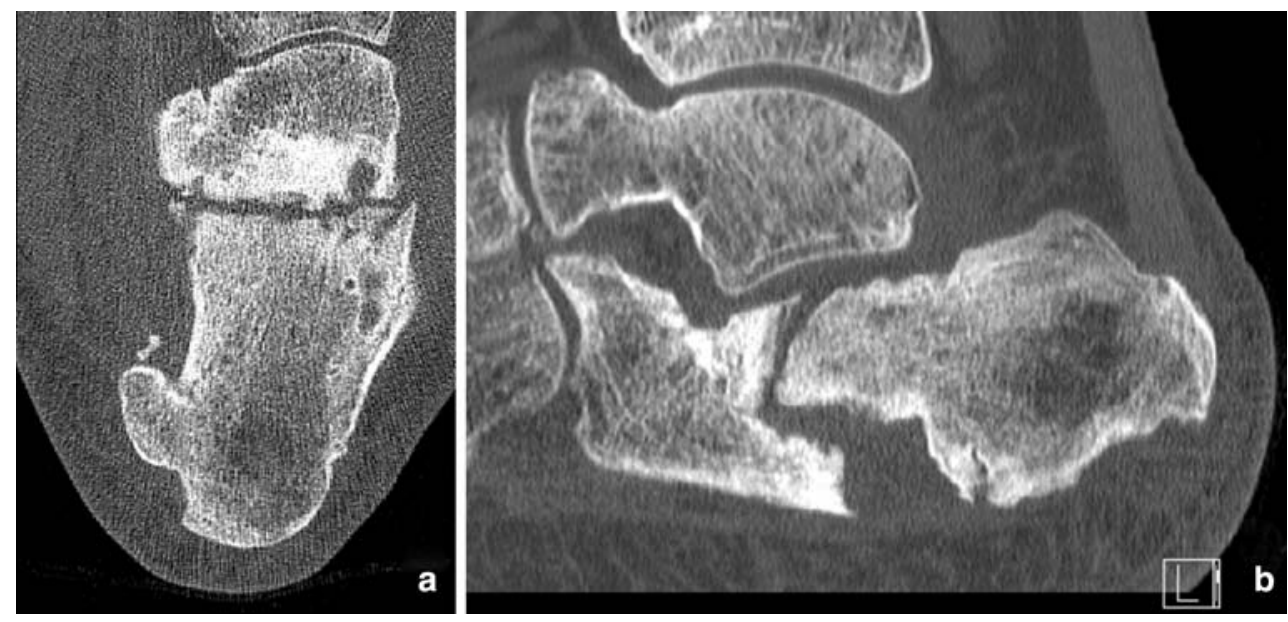

Fig. 3 a Case 3: Semi-coronal CT-scan image 13 months after conservative treatment showing nonunion; b Sagittal view

complications after intra-articular calcaneal fractures depends upon the presence of these conditions [13].

The first written report on calcaneal fracture nonunion was by Thomas (1993). He presented a 36-year-old female patient, treated non-operatively, who developed a calcaneal nonunion after 6 months [11]. A correction of the displaced fragment was performed and stabilized using plate osteosynthesis and bone graft. The patient was able to fully bear weight 12 weeks after this procedure.

Gehr described a 38-year-old male patient with an intraarticular, comminuted fracture of the calcaneus [3]. This fracture was treated with open reduction and internal plate osteosynthesis. After removal of the plate at 18 months the patient returned to the clinic with local swelling and pain during walking. A nonunion was seen and a correction osteotomy was performed with bone graft and screw fixation. The fracture showed healing at 8 weeks.

Karakurt et al. [6] presented one 42-year-old male patient with a nonunion of the calcaneus after conservative treatment. The patient sustained a comminuted, open calcaneal fracture which was treated in plastercast for 6 months. Eight months after trauma the patient was unable to walk without crutches because of severe pain of the heel. After removing fibrotic tissue the calcaneus was filled with bone graft. Eight months after the operation patient was able to walk and work without pain.

Zwipp and Rammelt [13] reported two patients with a nonunion of the calcaneus. A 61-year-old female patient, with a Sanders IIC fracture with a luxation of the tuberosity fragment, was treated conservatively. An arthrodesis of the subtalar and calcaneocuboid joint was performed 6 months after trauma. Postoperatively the American Orthopaedic foot and Ankle Society hindfoot score improved significantly, compared with pre-operative values. The second patient was a 45-year-old female polytrauma patient. After percutaneous reduction and fixation she was diagnosed with a nonunion 1 year after the trauma, for which a subtalar joint arthrodesis was performed. No data on outcome was provided in this case.

From cases described in literature and in the current report no similarities that could indicate a risk factor of nonunion could be found. There are no apparent similarities besides the nonunion (Table 1). There might be a trend of nonunion occurring after conservative treatment, suggesting
Table 1 Summary of patients presented in the literature after a calcaneal nonunion

\begin{tabular}{llrllr}
\hline Study & Gender & Age & Initial treatment & Salvage procedure & $\begin{array}{c}\text { Follow-up* } \\
\text { (months) }\end{array}$ \\
\hline Thomas and Wilson [11] & Female & 36 & Conservative & Osteotomy, plate, bone graft & 3 \\
Thermann et al. [10] & - & - & - & Subtalar arthrodesis & 62 \\
Gehr et al. [3] & Male & 38 & ORIF & Osteotomy, screws, bone graft & 2 \\
Karakurt et al. [6] & Male & 42 & Conservative & Bone graft & 8 \\
Zwipp and Rammelt [12] & Female & 61 & Conservative & Subtalar arthrodesis, & - \\
& & & & calcaneocuboid joint fusion & \\
& Female & 45 & Percutaneous & Subtalar arthrodesis & - \\
Current study & Male & 49 & Percutaneous & Subtalar arthrodesis & 14 \\
& Female & 53 & Conservative & Subtalar arthrodesis & 3 \\
& Male & 39 & Conservative & Subtalar arthrodesis & 6
\end{tabular}

* The follow-up period after the salvage procedure is given 
that less rigid or no fixation may play a role in causing fracture nonunion in the calcaneus. However Howard et al. [5] saw no cases of nonunion in a group of 164 intra-articular calcaneal fractures treated nonoperative. Patient age varied between 36 and 61, both sexes were affected equally often and initial treatment differed between patients. Karakurt et al. [6] suggested that smoking could be the cause of the nonunion. All patients in this report were smokers. For tibial fractures strong evidence exists for delayed fracture healing in smokers [4]. And a significant lower union-rate was seen after subtalar arthrodesis in smokers versus nonsmokers [2]. Assous et al. [1] however saw no difference in fracture healing between smokers and non-smokers in a small series of intra-articular calcaneal fractures treated operatively.

In contrast to the infrequent occurrence of the calcaneal nonunion, stated in the case reports above, Thermann et al. [10] describe an in incidence of $10 \%$ nonunion $(n=4 / 40)$ in a group of patients receiving a subtalar arthrodesis for persisting invalidating pain after an intra-articular calcaneal fracture. In these four patients the nonunion coincided with painful subtalar posttraumatic arthrosis, delineating the indication for a subtalar arthrodesis, instead of a correction osteotomy with internal fixation.

Calcaneal nonunion has been reported on infrequently in the literature, but the number of patients seen by Thermann, and our own series, suggests that the incidence might be higher than expected.

Open Access This article is distributed under the terms of the Creative Commons Attribution Noncommercial License which permits any noncommercial use, distribution, and reproduction in any medium, provided the original author(s) and source are credited.

\section{References}

1. Assous M, Bhamra MS (2001) Should Os calcis fractures in smokers be fixed? A review of 40 patients. Injury 32(8):631-632

2. Easley ME, Trnka HJ, Schon LC, Myerson MS (2000) Isolated subtalar arthrodesis. J Bone Joint Surg Am 82(5):613-624

3. Gehr J, Schmidt A, Friedl W (2000) Calcaneus pseudarthrosis: a clinical rarity. Unfallchirurg 103(6):499-503

4. Hoogendoorn JM, Simmermacher RK, Schellekens PP, van der Werken C (2002) Adverse effects if smoking on healing of bones and soft tissues. Unfallchirurg 105(1):76-81

5. Howard JL, Buckley R, McCormack R, Pate G, Leighton R, Petrie D, Galpin R (2003) Complications following management of displaced intra-articular calcaneal fractures: a prospective randomized trial comparing open reduction internal fixation with nonoperative management. J Orthop Trauma 17(4):241-249

6. Karakurt L, Yilmaz E, Incesu M, Serin E (2004) Pseudarthrosis of a calcaneus fracture; a case report. Acta Orthop Traumatol Turc 38(4):288-290

7. Lim EVA, Leung JPE (2001) Complications of intraarticular calcaneal fractures. Clin Orthop 391:7-16

8. Sanders R (2000) Displaced intra-articular fractures of the calcaneus. J Bone Joint Surg Am 82(2):225-250

9. Schepers T, Schipper IB, Vogels LMM, Ginai AZ, Mulder PGH, Heetveld MJ, Patka P (2007) Percutaneous treatment of displaced intra-articular calcaneal fractures. J Orthop Sci 12(1):22-27

10. Thermann H, Hufner T, Schratt HE, Held C, Tscherne H (1999) Subtalar fusion after conservative or surgical treatment of calcaneus fracture. A comparison of long-term results. Unfallchirurg 102(1):13-22

11. Thomas P, Wilson LF (1993) Non-union of an os calcis fracture. Injury 24(9):630-632

12. Zwipp H, Rammelt S (2006) Subtalar arthrodesis with calcaneus osteotomy. Orthopade 35:387-404

13. Zwipp H, Rammelt S, Barthel S (2004) Calcaneal fractures-open reduction and internal fixation (ORIF). Injury 35(Suppl 2):SB46SB54 